PUBLISHER CORRECTION

\title{
Publisher Correction: Two-qubit sweet spots for capacitively coupled exchange-only spin qubits
}

MengKe Feng (D), Lin Htoo Zaw (D) and Teck Seng Koh (iD)

npj Quantum Information (2021)7:132; https://doi.org/10.1038/s41534-021-00467-2

Correction to: npj Quantum Information https://doi.org/10.1038/ s41534-021-00449-4, published online 16 July 2021

The original PDF version of this Article contained typesetting errors in Eqs. (9) and (12) and incorrectly read as follows:

Equation (9)

$\hat{U}_{\text {CPHASE }}=(100001000010000-1), \hat{U}_{\mathrm{CNOT}}=(1000010000010010) \cdot(9)$

Equation (12)

$\widetilde{U}_{\text {int }}\left(t_{0}\right)=\hat{U}_{\text {int }}\left(t_{0}\right) \hat{U}_{\delta}\left(t_{0}\right)=\left(e^{-\mathrm{i} V_{1} t_{0}} 0000 e^{-i V_{2} t_{0}} 0000 e^{-i V_{3} t_{0}} 0000 e^{-i V_{4} t_{0}}\right)$ $\left(e^{-i \int_{0}^{t_{0}} \delta V_{1}(t \prime) d t \prime} 0000 e^{-i \int_{0}^{t_{0}} \delta V_{2}(t \prime) d t \prime} 0000 e^{-i \int_{0}^{t_{0}} \delta V_{3}(t \prime) d t \prime} 0000 e^{-i \int_{0}^{t_{0}} \delta V_{4}(t \prime) d t \prime}\right)$

The correct form of Eq. (9) is:

$\widehat{U}_{\mathrm{CPHASE}}=\left(\begin{array}{llll}1 & 0 & 0 & 0 \\ 0 & 1 & 0 & 0 \\ 0 & 0 & 1 & 0 \\ 0 & 0 & 0 & -1\end{array}\right), \widehat{U}_{\mathrm{CNOT}}=\left(\begin{array}{llll}1 & 0 & 0 & 0 \\ 0 & 1 & 0 & 0 \\ 0 & 0 & 0 & 1 \\ 0 & 0 & 1 & 0\end{array}\right)$.

The correct form of Eq. (12) is:

$\widetilde{U}_{\text {int }}\left(t_{0}\right)=\hat{U}_{\text {int }}\left(t_{0}\right) \hat{U}_{\delta}\left(t_{0}\right)$

$$
=\left(\begin{array}{llll}
\mathrm{e}^{-\mathrm{i} V_{1} t_{0}} & 0 & 0 & 0 \\
0 & \mathrm{e}^{-\mathrm{i} V_{2} t_{0}} & 0 & 0 \\
0 & 0 & \mathrm{e}^{-\mathrm{i} V_{3} t_{0}} & 0 \\
0 & 0 & 0 & \mathrm{e}^{-\mathrm{i} V_{4} t_{0}}
\end{array}\right)
$$

$\left(\begin{array}{cccc}\mathrm{e}^{-i \int_{0}^{t_{0}} \delta V_{1}\left(t^{\prime}\right) d t^{\prime}} & 0 & 0 & 0 \\ 0 & \mathrm{e}^{-i \int_{0}^{t_{0} \delta V_{2}\left(t^{\prime}\right) d t^{\prime}}} & 0 & 0 \\ 0 & 0 & \mathrm{e}^{-i \int_{0}^{t_{0} \delta} \delta V_{3}\left(t^{\prime}\right) d t^{\prime}} & 0 \\ 0 & 0 & 0 & \mathrm{e}^{-\mathrm{i} \int_{0}^{t_{0} \delta} \delta V_{4}\left(t^{\prime}\right) d t^{\prime}}\end{array}\right)$

In the in-line equation right below Eq. (12), the tilde on the second $\mathrm{U}$ was rendered across " $\mathrm{U}$ ", instead of above it. It incorrectly read:

$\mathcal{F}=\frac{1}{d^{2}}\left|\operatorname{Tr}\left(U^{\dagger} \boldsymbol{U}\right)\right|^{2}$

The correct form of this equation is:

$\mathcal{F}=\frac{1}{d^{2}}\left|\operatorname{Tr}\left(U^{\dagger} \tilde{U}\right)\right|^{2}$

The equation label "(12)" was also incorrectly omitted.

This has now been corrected in the PDF version of the Article. The HTML version is correct and remains unchanged.

(i) Open Access This article is licensed under a Creative Commons Attribution 4.0 International License, which permits use, sharing, adaptation, distribution and reproduction in any medium or format, as long as you give appropriate credit to the original author(s) and the source, provide a link to the Creative Commons license, and indicate if changes were made. The images or other third party material in this article are included in the article's Creative Commons license, unless indicated otherwise in a credit line to the material. If material is not included in the article's Creative Commons license and your intended use is not permitted by statutory regulation or exceeds the permitted use, you will need to obtain permission directly from the copyright holder. To view a copy of this license, visit http://creativecommons. org/licenses/by/4.0/.

(c) The Author(s) 2021 